\title{
Toward estimating the impact of changes in immigrants' insurance eligibility on hospital expenditures for uncompensated care Liana D Castel ${ }^{1}$, Justin W Timbie ${ }^{1,2}$, Veronica Sendersky ${ }^{1,3}$, Lesley H Curtis ${ }^{1}$, Keith A Feather ${ }^{4}$ and Kevin A Schulman*1
} \begin{abstract}
Management, Box 3647, Duke University Medical Center, Durham, NC 27710 USA
Email: Liana D Castel - liana.castel@duke.edu; Justin W Timbie - timbie@fas.harvard.edu; Veronica Sendersky - veronica.sendersky@pharma.novartis.com; Lesley H Curtis - lesley.curtis@duke.edu; Keith A Feather - feath001@mc.duke.edu; Kevin A Schulman* - kevin.schulman@duke.edu

* Corresponding author
\end{abstract}

Address: ${ }^{1}$ Center for Clinical and Genetic Economics, Duke Clinical Research Institute, Duke University Medical Center, PO Box 17969 , Durham, NC 27715 USA, 2 PhD Program in Health Policy, Harvard University, 79 John F. Kennedy Street, Cambridge, MA 02138 USA, ${ }^{3}$ Department of Health Care Management, Novartis Pharmaceuticals Corporation, 59 Route 10, East Hanover, NJ 07936 USA and ${ }^{4}$ Department of Patient Resource

Published: 10 January 2003

BMC Health Services Research 2003, 3:1

This article is available from: http://www.biomedcentral.com/I472-6963/3//

(C) 2003 Castel et al; licensee BioMed Central Ltd. This is an Open Access article: verbatim copying and redistribution of this article are permitted in al media for any purpose, provided this notice is preserved along with the article's original URL.
Received: 16 October 2002

Accepted: 10 January 2003

\begin{abstract}
Background: The Personal Responsibility and Work Opportunity Reconciliation Act (PRWORA) of 1996 gave states the option to withdraw Medicaid coverage of nonemergency care from most legal immigrants. Our goal was to assess the effect of PRWORA on hospital uncompensated care in the United States.

Methods: We collected the following state-level data for the period from 1994 through 1999: foreign-born, noncitizen population and health uninsurance rates (US Census Current Population Survey); percentage of teaching hospitals (American Hospital Association Annual Survey of Hospitals); and each state's decision whether to implement the PRWORA Medicaid bar for legal permanent residents or to continue offering nonemergency Medicaid coverage using state-only funds (Urban Institute). We modeled uncompensated care expenditures by state (also from the Annual Survey of Hospitals) in both univariate and multivariable regression analyses.

Results: When measured at the state level, there was no significant relationship between uncompensated care expenditures and states' percentage of noncitizen immigrants. Uninsurance rates were the only significant factor in predicting uncompensated hospital care expenditures by state.

Conclusions: Reducing the number of uninsured patients would most surely reduce hospital expenditures for uncompensated care. However, data limitations hampered our efforts to obtain a monetary estimate of hospitals' financial losses due specifically to the immigrant eligibility changes in PRWORA. Quantifying the impact of these provisions on hospitals will require better data sources.
\end{abstract}

\section{Background}

The Personal Responsibility and Work Opportunity Reconciliation Act (PRWORA) of 1996 (US Public Law 104-
93) aimed to reduce federal welfare expenditures by changing eligibility criteria for public assistance. An important provision in the legislation determined that legal 
immigrants entering the United States on or after August 22, 1996, would no longer be eligible for nonemergency Medicaid services. While PRWORA may have achieved substantial federal welfare savings [1], there has been little investigation of its financial impact on hospitals that provide nonemergency services to medically uninsured legal immigrants.

A news story in 2000 highlighted instances in which documented and undocumented immigrants without health insurance remained in acute-care facilities after recovery, often resulting in hundreds of thousands of dollars in uncompensated care costs for the hospitals involved [2]. Because uninsured immigrants affected by PRWORA are eligible only for emergency Medicaid, they lack coverage for any form of postdischarge medical care (eg, acute rehabilitation, medical equipment, follow-up outpatient or home health care, and transfer to long-term care facilities or nursing homes) [2]. Since these services often constitute the prevailing standard of care for chronic or disabling conditions, hospitals may incur substantial expenses by keeping Medicaid-ineligible patients in acutecare facilities longer than necessary due to lack of suitable long-term care or rehabilitation options [2].

Another news story in 2001 presented cases of legal immigrants who, due to PRWORA, could access funding for nonemergency health care and prescription drugs only through local safety net providers. The quality of these immigrants' health care and the availability of subsidized services varied widely according to the regional distribution of safety net providers and the range of services offered [3].

Several studies have investigated the impact of PRWORA on Medicaid and/or welfare participation and patients' access to care [4-8], but none have examined the impact of PRWORA on hospitals. A report by the New York Immigration Coalition [9], as well as discussions by the Greater New York Hospital Association and the media suggest that the PRWORA provisions have had a negative financial impact on hospitals, especially those serving large immigrant populations $[2,11,12]$. In their 2000 case study examining hospitals' ability to meet rising demands for uncompensated care, the authors of the United Hospital Fund report put forward that in New York City, uncompensated care expenses would be expected to increase due to growth in numbers of immigrants ineligible for Medicaid coverage due to welfare reform [10]. Estimating the extent of projected financial loss to hospitals due to this specific policy provision is important to both hospitals and state policymakers as the legislation is renewed and reexamined.

\section{Origins of PRWORA}

In the 1990s, Congress moved to reform public spending by reducing the number of beneficiaries on welfare rolls. Reforms focused partly on immigrants, following testimony from the General Accounting Office estimating that slightly more than half of the Supplemental Security Income (SSI) benefits provided to elderly persons were collected by noncitizens in 1995 [13,14]. In justifying PRWORA [15], the House Ways and Means Committee stated that it had been a basic tenet of US immigration policy since 1882 that legal immigrants should not be eligible for public benefits. Though Congress did not rescind emergency Medicaid from illegal immigrants, the legislation cited "a compelling government interest to remove the incentive for illegal immigration provided by the availability of public benefits" [13]. PRWORA was among several pieces of legislation in the mid-1990s - including California's Proposition 187 in 1994 and the Illegal Immigration Reform and Immigrant Responsibility Act of 1996 [16] - that embodied substantive immigration policy changes, the specific provisions of which have been enforced in varying degrees according to government priorities.

\section{PRWORA legislation and states' responses}

PRWORA made several key reforms restricting public assistance for qualified immigrants [17]. Prior to the implementation of PRWORA, "qualified aliens" were eligible for the same federal means-tested benefits as US citizens. PRWORA makes an important distinction between "qualified" and "non-qualified" immigrants. The term qualified alien is used synonymously with legal immigrant and designates a noncitizen who falls into one of the following categories: (1) persons lawfully admitted for permanent residence; (2) persons granted asylum; (3) refugees; (4) persons paroled into the United States for at least one year; (5) persons for whom deportation is being withheld; and (6) persons granted conditional entry. The term nonqualified alien includes nonimmigrant visitors and undocumented/illegal immigrants.

After PRWORA, legal immigrants were declared ineligible for nonemergency Medicaid for their first 5 years in the country, with some exceptions, as described later. The Immigration and Naturalization Service (INS) estimates that there were 10.5 million $( \pm 350000)$ legal permanent residents residing in the United States as of April 1996 [18]. To qualify for Medicaid coverage after the ban, noncitizens must not receive public benefits during the 5 -year period [15]. Legal immigrants receiving benefits at the time of enactment on August 22, 1996, were denied continuation of those benefits starting January 1, 1997. Benefits both before and after PRWORA for non-qualified aliens remained restricted to emergency Medicaid. 
Before PRWORA, states did not consider immigration status in granting Medicaid assistance. After PRWORA, however, most legal immigrants arriving after August 1996 were barred from Medicaid and other state-funded assistance, at states' discretion. Exceptions were made for (1) refugees; (2) persons granted asylum and persons whose deportation was being withheld; (3) armed forces personnel or veterans and their dependent family members; and (4) legal permanent residents with 40 qualifying quarters of work [15].

Under pressure from the White House and immigrants' advocacy groups, Congress restored some Medicaid benefits to certain legal immigrants as part of the Balanced Budget Act (BBA) of $1997[19,20]$. Under the BBA, a legal immigrant could qualify for Medicaid (not restricted to emergency Medicaid) through SSI eligibility if he or she was lawfully in the United States and receiving SSI benefits on August 22, 1996, and subsequently certified under the SSI program as blind or disabled.

\section{Immigrant populations and use of health care}

Noncitizens in the United States numbered approximately 17.8 million in 2000, or 6.5 percent of the total population [21]. Previous research has shown noncitizens to be more economically disadvantaged and to possess lower levels of health insurance than naturalized and native citizens. Census data suggest that noncitizens are more likely than citizens to be poor ( $29 \%$ vs $16 \%$ ), despite the fact that noncitizen families are as likely as citizen families to have at least one full-time worker ( $82 \%$ vs $85 \%$ ) [22]. In their report on insurance rates for Hispanic immigrants, the Commonwealth Fund Task Force on the Future of Health Insurance found that the longer Hispanic immigrants had been permanent residents of the United States, the more likely they were to be covered by employer-related insurance [23]. Among low-income immigrants in the United States in $1999,59 \%$ were uninsured, compared to $30 \%$ of low-income citizens [22]. The Kaiser Commission reports that immigrants may underutilize health care regardless of insurance coverage, out of fear of jeopardizing their citizenship eligibility by incurring costs as public charges [22].

\section{Objective}

Using data from several sources, we present snapshots of information currently available, and consider how the financial impact of PRWORA on hospitals might be estimated. Based on a review of relevant literature, we hypothesized that uncompensated hospital care would be more prevalent in states with lower rates of health insurance coverage, higher percentages of foreign-born residents (used to approximate the population of interest affected by PRWORA), higher rates of poverty, and greater percentages of teaching hospitals [22-26]. We outline the limitations of available data and discuss what information is needed to accurately estimate the outcome of interest.

\section{Methods}

Our goal was to examine the effects of PRWORA on hospital uncompensated care expenditures. The analysis consisted of two parts: a series of "data snapshots" to describe relevant information, and a multivariable regression to model drivers of uncompensated care costs. The regression analysis was conducted at the state level because no single source of data includes both patients' immigration status and the amount of uncompensated hospital care provided, thus precluding hospital- or patient-level analyses.

We collected the following state-level data for the period from 1994 through 1999: foreign-born, noncitizen population; health uninsurance rates; percentage of teaching hospitals as a proportion of all hospitals reporting data per state; and each state's decision regarding whether to implement the PRWORA Medicaid bar for legal permanent residents or to continue offering nonemergency Medicaid coverage using state-only funds. These factors are thought to influence expenditures per admission for uncompensated hospital care [22-26] and were examined at the state level for the period from 1994 to 1999 for a total of 300 observations ( 6 years $\times 50$ states).

State-level data on the percentage of the population uninsured and the percentage of the population comprised of foreign-born noncitizens were obtained from the 2000 Current Population Survey, March Supplement, a detailed description of which is available elsewhere [21]. Because the Medicare program covers virtually all Americans aged 65 and older, data on insurance coverage rates among nonelderly populations were used. As the closest available proxy for the percentage of legal immigrants per state, we used the "foreign born, not a US citizen" category available in the Public Basic Monthly Survey for 1994 to 2001.

State-level poverty data were obtained from the historical poverty tables of the Census Bureau [29]. Poverty thresholds are stable across all regions and are adjusted for inflation every year using the Consumer Price Index for All Urban Consumers (CPI-U).

Aggregate data on uncompensated care were obtained from the American Hospital Association's (AHA) nationwide Annual Survey of Hospitals [30]. AHA defines bad debt as the provision for actual or expected uncollectibles resulting from the extension of credit. Charity care services, however, are provided free of charge to individuals who meet certain financial criteria and are never expected to result in cash inflows. Total uncompensated care for 
hospitals on the state level was estimated as the sum of bad debt and charity care. For each state, we obtained a sample of all hospitals for which both charity care and bad debt data were available yearly from 1994 to 1999 . We calculated uncompensated care per hospital admission as a per capita estimate of uncompensated care. These estimates were adjusted to 1999 US dollars using the medical care component of the CPI.

Teaching hospital status also was obtained from the AHA Annual Survey of Hospitals. The AHA defines teaching hospitals as those that are members of the Council of Teaching Hospitals of the Association of American Medical Colleges. Teaching hospital percentage refers to the percentage of hospitals classified as teaching hospitals out of the total number of hospitals in a state reporting data to AHA for the years of interest.

Although every state, excluding Wyoming and South Dakota, chose to preserve Medicaid coverage for immigrants who were eligible before the enactment of PRWORA (i.e., entering the United States before August 22, 1996), states' decisions varied on whether to implement the 5-year bar on Medicaid eligibility for qualified immigrants after the enactment of PRWORA. Fourteen states (California, Connecticut, Delaware, Hawaii, Illinois, Maine, Maryland, Massachusetts, Minnesota, Nebraska, Pennsylvania, Rhode Island, Virginia, and Washington) maintained Medicaid eligibility for qualified immigrants entering the United States after August 22, 1996, through state-only funds [31]. We included a dichotomous variable in the model describing each state's implementation decision.

A multiple regression analysis was conducted to test the hypothesis that total uncompensated care (the sum of charity care and bad debt) per admission would be affected by a state's percentage of foreign-born residents, poverty rate, uninsurance rate, percentage of hospitals, and the state's implementation decision. Because total uncompensated care was heavily skewed, we used a log-transformed variable as the dependent variable. The resulting log-linear model has the convenient property of measuring the relative change in the dependent variable (uncompensated care) for an absolute change in a given predictor variable, controlling for other predictors in the model. Each year from 1994 through 1999 was entered into the model as a categorical variable, omitting 1994 as the reference year. We used the Huber [32] and White estimator $[33,34]$, clustered on states, to obtain robust error estimates that allow for the lack of independence of observations within a given state over time.

Statistical analyses were performed using STATA version 6.0 (Stata Corporation, College Station, Tex) and SPLUS statistical software (Insightful Corporation, Seattle,
Wash). This project was approved by the institutional review board of Duke University Medical Center.

\section{Results \\ Data snapshots: state population and hospital character- istics \\ Immigrant population}

Figure 1 displays the percentage of immigrants for each state, according to US Census data. States with the highest percentages of foreign-born noncitizens in 1994 were California $(18.4 \%)$, New York (10.9\%), Florida (9.6\%), Rhode Island $(8.4 \%)$, and Nevada $(8.4 \%)$. The national mean was 3.2 percent (SD, 3.59).

\section{Health insurance coverage}

The total number of medically uninsured persons living in the United States is estimated to be 42.5 million, or $16 \%$ of the population [22]. As shown in Figure 2, the states with the highest percentages of uninsured residents in 1994 were Texas (24.8\%), New Mexico (23.5\%), California $(21.2 \%)$, Arizona $(20.5 \%)$, and Alabama (19.4\%). Texas and California are also among the states with the highest percentage of foreign-born residents, although California did not implement PRWORA's Medicaid eligibility bar.

\section{State implementation decisions}

Of the 6 states with the highest immigrant populations (70\% of the total immigrant population of the United States), California and Illinois were the only states that preserved Medicaid coverage for qualified immigrants through state-only funds [22]. Thirty-six states eliminated Medicaid coverage during the 5-year bar $[7,31]$

\section{Poverty}

Figure 3 displays the poverty rate for each state, according to US Census data. The national average was 13.1 (SD, 3.93). Three of the 10 states with the highest poverty rates in 1994 were also among the states with the highest percentage of foreign-born residents - Texas (19\%), California $(18 \%)$, and New York (17\%).

\section{Uncompensated care}

Figure 4 shows the amount of uncompensated care per admission provided by the states with the highest numbers of legal permanent residents (California, Florida, Illinois, New Jersey, New York, and Texas) from 1994 through 1999 and the average uncompensated care cost per year for the three-year periods before and after PRWORA's enactment.

\section{Regression model}

Exploratory analyses showed that uninsurance was highly correlated with the state's poverty rate $(r=0.70)$. In addition, percentage foreign-born and percentage teaching 


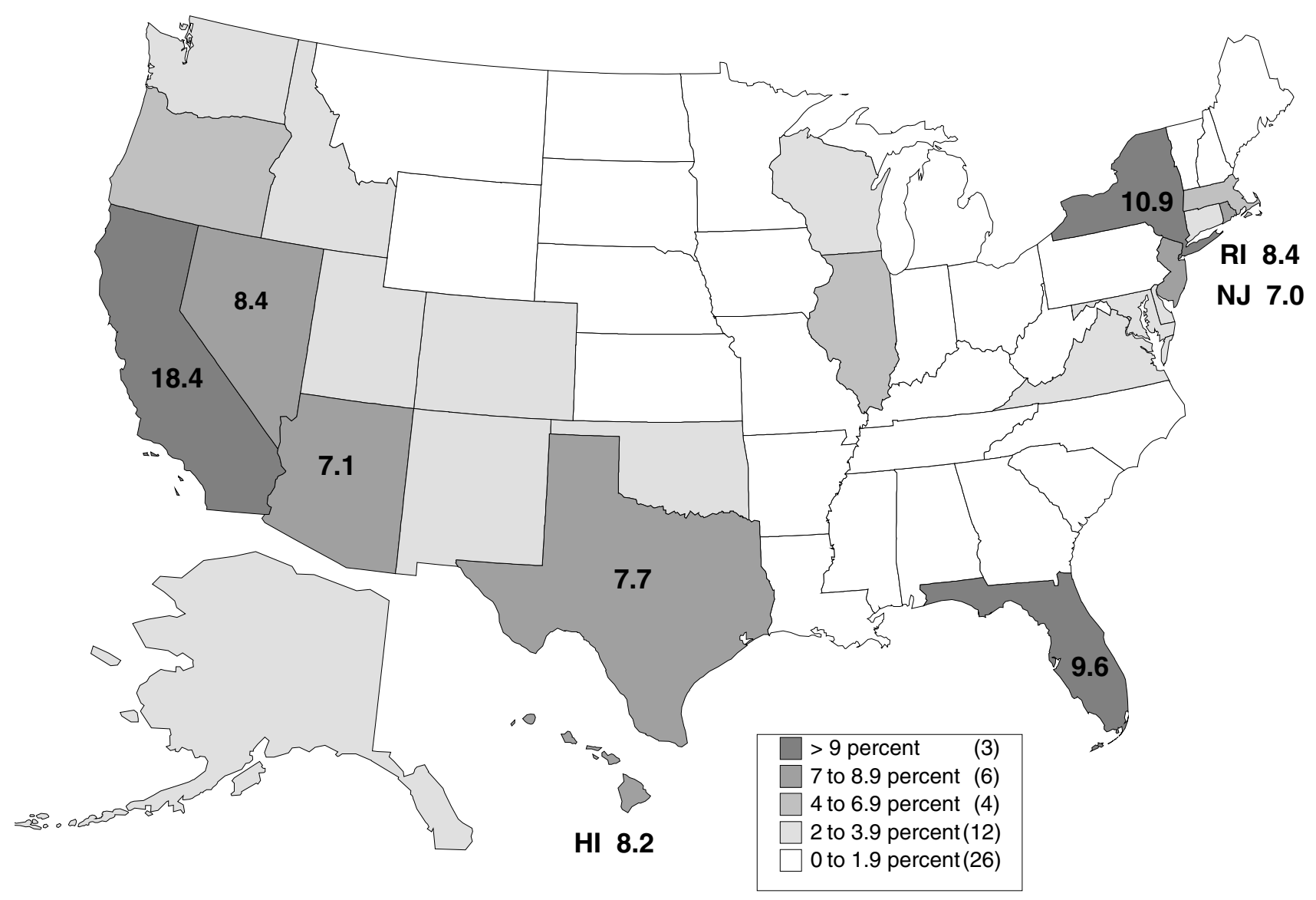

Figure I

Percentage of Foreign-Born, Noncitizen Residents by State, 1994

hospitals were highly correlated $(r=0.30)$. To avoid collinearity and create a more robust model, poverty rate was dropped from the final multivariable regression model; percentage of teaching hospitals was dichotomized, assigning a value of 1 to states with $5 \%$ or more teaching hospitals. Both the dependent variable - uncompensated care per admission - and percentage foreign-born were used in log form due to nonnormal distributions revealed in exploratory analyses.

Results of the multivariable regression modeling (Table 1) suggest that, controlling for time and a state's foreignborn population, percentage of teaching hospitals, and implementation decision, a $1 \%$ increase in a state's uninsured population yields a $4.1 \%$ increase in the amount of uncompensated care provided $(P<.001)$. Controlling for all other variables, a $1 \%$ increase in the log of a state's foreign-born population yields a $2.2 \%$ increase in uncompensated care, though this result was only significant at the .10 level. Percentage of teaching hospitals greater than $5 \%$ was found to be a weak predictor of uncompensated care, but was not significant $(P=.601)$. A state's decision to implement PRWORA did not independently predict uncompensated care expenditures in our model. The trend variables corresponding to years were not significant.

\section{Discussion}

PRWORA marked large-scale changes in health, immigration, and welfare policy in the United States. Patients, hos- 


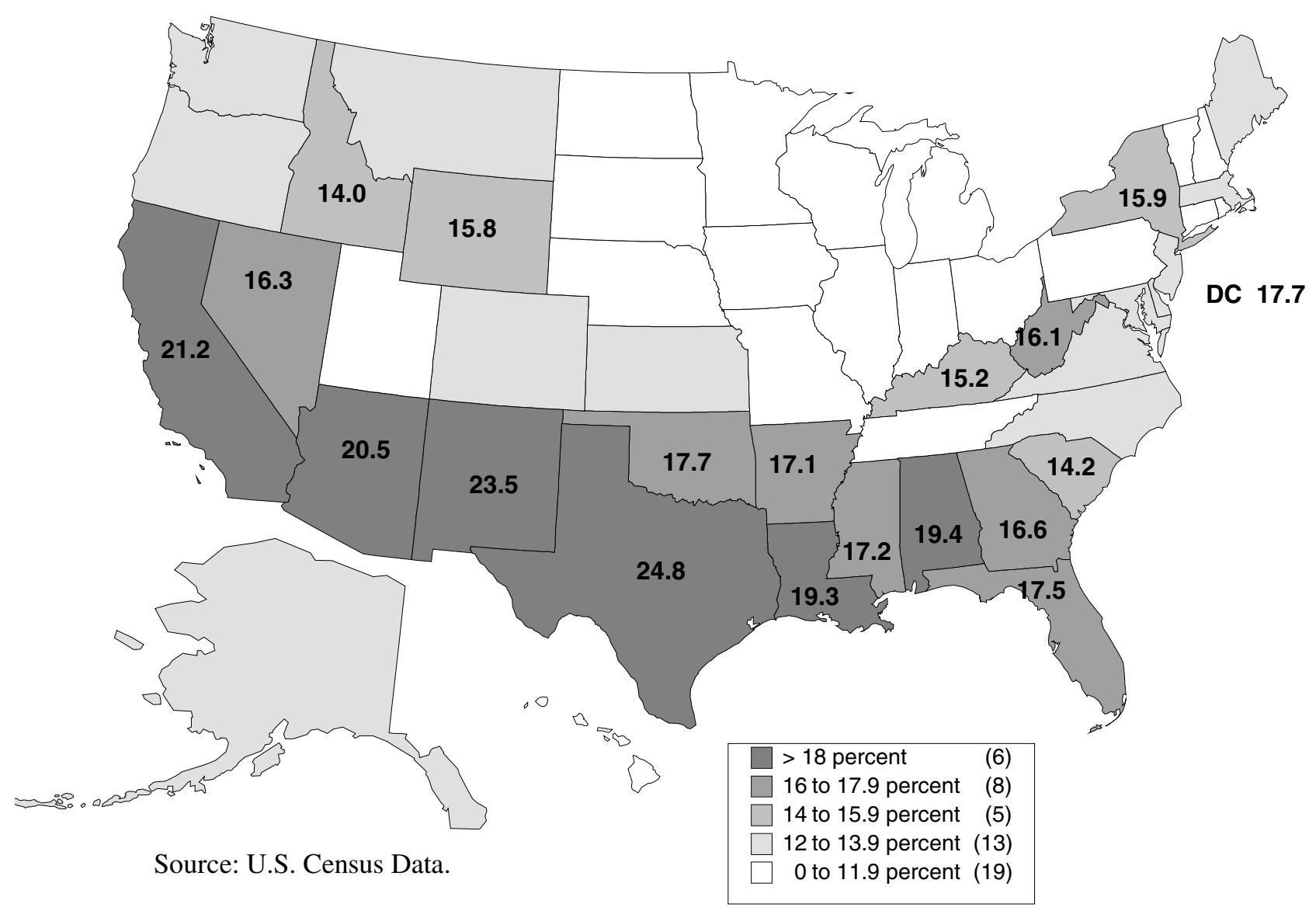

Figure 2

Percentage of Uninsured Residents by State, 1994

pitals, and state and federal governments have all had a stake in PRWORA's enactment. An accurate monetary estimate of the effects of PRWORA on hospital uncompensated care due to changes in Medicaid coverage would be useful to policymakers as PRWORA periodically comes up for consideration of renewal, and as anecdotal evidence of an adverse financial impact on hospitals continues to mount.

We hypothesized that hospital uncompensated care expenditures would be greater in states with higher percentages of foreign-born residents, lower rates of insurance coverage, and higher percentages of teaching hospitals.
Measured at the state level, hospital uncompensated care expenditures were not statistically significantly related to percentage foreign-born, percentage of teaching hospitals, or states' implementation decisions; in our model, higher uninsurance rates emerged as the only significant predictor of uncompensated hospital care expenditures. This finding suggests that efforts to reduce the number of people uninsured or underinsured would reduce hospitals' expenditures on uncompensated care. This implication reinforces claims that high rates of uninsurance in United States have negative effects, but does not directly address our original hypothesis about the immigrant eligibility provisions of PRWORA. As with other studies that have 


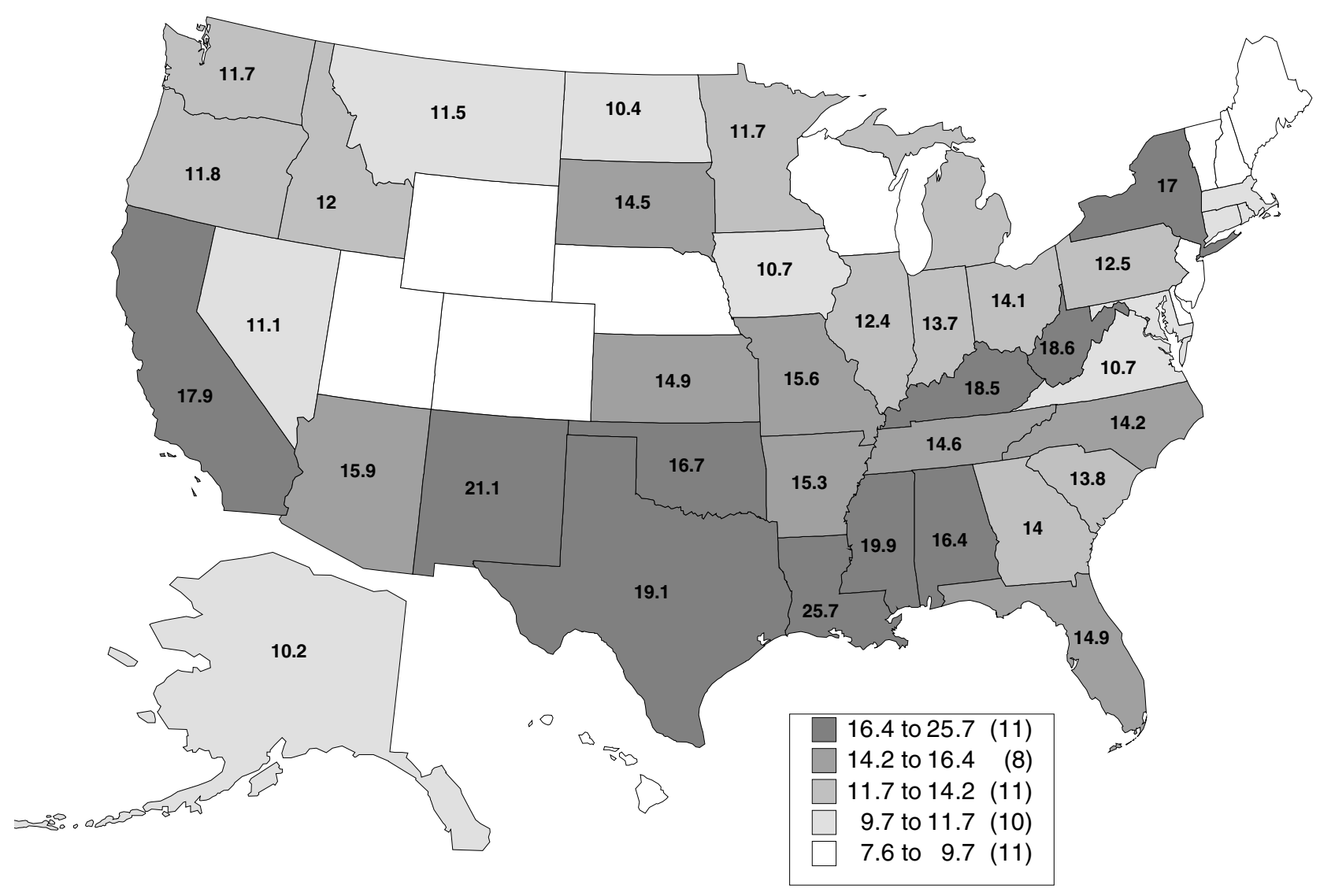

Figure 3

Poverty Rate by State, 1994

combined disparate data sources to assess the impact of PRWORA on the health or welfare of would-be beneficiaries [4], data limitations posed a significant challenge to these analyses.

The proxy of percentage foreign-born may not have accurately captured the population of interest - legal immigrants arriving after August 22, 1996, who were no longer eligible for nonemergency Medicaid coverage. Using the foreign-born category from the Census data relies on the assumption that states with higher foreign-born populations would also have a greater number of legal immigrants whose eligibility for nonemergency Medicaid would be affected by PRWORA. However, the foreignborn noncitizen category used in Census data (defined as any person not born a citizen of the United States and not naturalized) includes categories of persons exempted from PRWORA's Medicaid cuts, such as asylum seekers and refugees. Given that PRWORA requires states that provide health services to report illegal immigrants to authorities, it is unlikely that accurate data on immigration status and date of entry into the United States can be collected in the health care setting. In addition, it is unlikely that any institutional review board would approve the collection of such data in present circumstances.

Because the main effect of PRWORA was to restrict Medicaid eligibility, thereby increasing demand for uncompensated care, the present analysis focused on state-level parameters linked to demand for medical care. Uncom- 


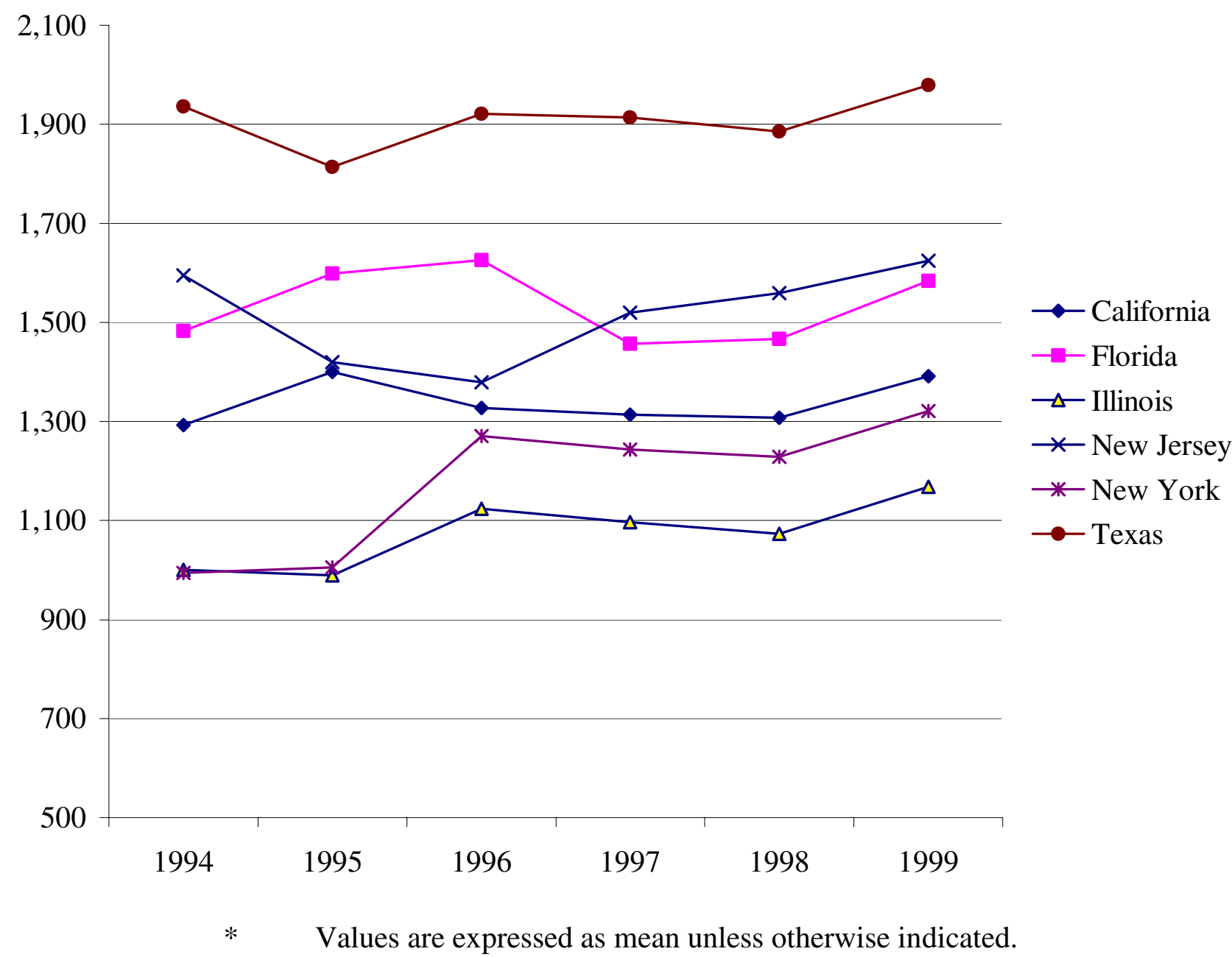

\section{Figure 4}

Uncompensated Care Expenditures Per Admission, 1994-1999. Uncompensated Care Expenditures Per Admission in States With the Most Legal Permanent Residents at the Time of PRWORA Enactment, 1994-1999*

pensated care reimbursement pools, common in states with former all-payer rate-setting systems, led to increased uncompensated care expenditures throughout the 1990s. In a deregulated health care system, however, states tended to use these funds to expand Medicaid and/or Medicaid managed care, thus shifting the focus of the pools to reimbursement for charity care only [35]. Because of the nonuniformity of states' approaches to uncompensated care pools, their limited use, and their changing roles over time, we did not include this factor in our final model.

A monetary estimate on a national, state, or hospital level of the financial impact of PRWORA remains difficult to ascertain due to data limitations. Ideally, such research would compare the costs before and after 1996 of the nonemergency care that hospitals provided (both as charity care and as bad debt) to the category of immigrants who lost nonemergency Medicaid eligibility due to the implementation of PRWORA. We would expect the extent and implications of this financial impact to vary according to both hospital characteristics and the populations served. Because a patient's immigration status is not recorded concomitantly with hospital resource use in any hospital, state, or federal database, it is not currently possible to isolate charity care and bad debt expenditures on 
Table I: Predictors of Hospital Charity Care Before and After Enactment of PRWORA

\begin{tabular}{llc}
\hline \multicolumn{1}{c}{ Variable } & $(95 \% \mathrm{Cl})$ & $P$ \\
\hline Year & & 0.577 \\
1995 & $0.01(-0.04-0.06)$ & 0.732 \\
1996 & $0.01(-0.05-0.08)$ & 0.947 \\
1997 & $-0.01(-0.17-0.16)$ & 0.679 \\
1998 & $0.03(-0.13-0.20)$ & 0.433 \\
1999 & $0.07(-0.10-0.23)$ & 0.076 \\
Percentage foreign-born residents* & $2.17(-0.23-4.57)$ & 0.000 \\
Percentage of population uninsured $\dagger$ & $4.09(2.00-6.18)$ & 0.601 \\
$>5 \%$ teaching hospitals & $0.47(-1.32-2.26)$ & 0.646 \\
Implementation decision $\ddagger$ & $-0.05(-0.28-0.18)$ & \\
\hline
\end{tabular}

* Logarithm value used in model to handle non-normal distribution $\dagger$ Significant at $\alpha<0.05$. $\ddagger$ Variable is dichotomous Note: $\mathrm{Cl}$ indicates confidence interval.

nonreimbursed services for patients whose eligibility for Medicaid has been changed by PRWORA.

An additional complicating factor is the possibility that, as a result of PRWORA, hospitals may provide and bill for services as emergency services that previously were categorized as nonemergency services in order to secure Medicaid payment. Similarities in income-related eligibility criteria for emergency and nonemergency Medicaid would facilitate reclassification. Further research should examine the extent to which providers reclassify services.

Traditionally, safety net hospitals have been supported though public funds, such as disproportionate-share hospital (DSH) payments. The Medicaid DSH payment is based on the assumption that certain hospitals, in addition to providing care to Medicaid enrollees, also serve indigent persons who are ineligible for Medicaid. However, there are some indications that public support mechanisms to hospitals may be in jeopardy [36]. First, DSH payments are large and repeatedly become targets for budget cuts by federal and state governments. As a result of provisions in the BBA, for example, it has been estimated that federal spending on Medicaid DSH will decrease by $11 \%$, or $\$ 5.8$ billion, during the period from 1998 through 2002. Since more Medicaid beneficiaries are being cared for in private facilities, public safety net hospitals may be affected by both competition for fee-forservice patients and decreases in overall DSH allotments [37]. Finally, safety net hospitals typically use Medicaid revenues to help fund uncompensated care; decreases in Medicaid reimbursements may, therefore, further impede hospitals' ability to provide services to the uninsured [38].

Existing studies of trends in uncompensated hospital care expenditures have focused primarily on supply-side covariates, such as uncompensated care pools, Medicare and
Medicaid DSH payments, and the degree of competition in the local health care marketplace $[25,28,36,39,40]$. While a focus on such hospital characteristics has helped to elucidate the factors that affect uncompensated care at the hospital level, the present study sought to examine the impact of the PRWORA legislation by identifying statelevel characteristics affecting total hospital uncompensated care per state from 1994 to 1999. Because data used for the regression model came from multiple sources, comprehensive year-by-year figures from 1994 through 1999 were available for all factors in the model only at the state level. Because PRWORA gave states the option of changing Medicaid coverage, state-level information is useful in understanding how PRWORA was implemented across the United States. However, to better assess the effects of PRWORA on hospitals, detailed hospital-specific information, at least at the level of metropolitan statistical area (MSA), would be needed on the immigration status of populations served. Data limitations currently hamper efforts to obtain a monetary estimate of hospitals' financial losses due specifically to PRWORA. To better quantify the impact of health policy regulations on health care providers, better data sources, particularly at the MSA level, are needed.

\section{Competing interests}

None declared.

\section{Authors' Contributions}

LDC conceived of and designed the study, performed the statistical analysis, interpreted the data, and drafted the manuscript. JWT, VS, and LHC assisted in the statistical analysis, interpretation of data, and drafting of the article. KAF and KAS conceived of and designed the study and obtained funding. All authors read and approved the final manuscript. 


\section{Acknowledgments}

The authors thank Damon Seils for editorial assistance and manuscript preparation.

This work was presented as a poster at the Annual Research Meeting of the Academy for Health Services Research and Health Policy, Washington, DC, June 23-35, 2002.

\section{References}

I. U.S. Congressional Budget Office The Economic and Budget Outlook : An Update, August 1996. Washington, DC 1996,

2. Lagnado L Medicaid "fix" binds immigrants in system many find appalling. Wall Street Journal A IOctober 182000

3. Newman B Lost in America: quirk in law creates health-care minefield for legal immigrants. Wall Street Journal AIAugust 29 2001

4. Borjas GJ Food Insecurity and Public Assistance. Los Angeles, Center for Comparative Social Analysis, UCLA Department of Sociology 2001,

5. Ellwood MR and Ku L Welfare and immigration reforms: unintended side effects for Medicaid. Health Aff |998, I 7:| 37-|5|

6. Ku L and Garrett B How Welfare Reform and Economic Factors Affected Medicaid Participation: 1984-96. Washington, DC, The Urban Institute 2000,

7. Ku L and Matani S Immigrants' Access to Health Care and Insurance on the Cusp of Welfare Reform. Washington, DC, The Urban Institute 2000,

8. Zimmermann $W$ and Fix $M$ Declining Immigrant Applications for Medi-Cal and Welfare Benefits in Los Angeles County. Washington, DC, The Urban Institute 1998 ,

9. New York Immigration Coalition Welfare Reform and Health Care: The Wrong Prescription for Immigrants. New York, NY, New York Immigration Coalition/Solutions for Progress 2000,

10. Prinz TS, Haslanger K, DeLia D, Fass S, Salit S and Cantor JC Hospital Markets, Policy Change, and Access to Care for Low-Income Populations in New York. New York, NY, United Hospital Fund 2001,

II. 200I Federal Priority Issues: GYNHA Federal Legislative Agenda 200I: Hospitals. Greater New York Hospital Association Web site 20 December 2002

12. Serafini MW Welfare law could cost hospitals. Natl J 1996 28:2066-2067

13. Committee on Ways and Means U.S. House of Representatives Summary of Welfare Reforms Made by Public Law I 04- 193 The Personal Responsibility and Work Opportunity Reconciliation Act and Associated Legislation. Washington, DC, U.S. Government Printing Office 1996,

14. U.S. General Accounting Office Supplemental Security Income: Noncitizen Caseload Continues to Grow. Report No. GAOI T-HEHS-96- I 49. Washington, DC 1996 ,

15. U.S. Public Law 104-193, Sec. 431, 104th Cong., 2d sess., Personal Responsibility and Work Opportunity Reconciliation Act of 199622 August 1996

16. Illegal Immigration Reform and Immigrant Responsibility Act, Pub L No. I 04-208, I I OStat3009-546

17. Office of the Assistant Secretary for Planning and Evaluation U.S. Department of Health and Human Services Comparison of Prior Law and the Personal Responsibility and Work Opportunity Reconciliation Act of 1996 (P. L. I 04-193). Washington, DC 200I, Accessed 20 December 2002.

18. U.S. Immigration and Naturalization Service Triennial Comprehensive Reports on Immigration. Washington, DC 1999, Accessed 20 December 2002.

19. Balanced Budget Act of 1997,. Pub L No. 105-33, I I I Stat 350

20. National Health Law Program, National Center for Youth Law National Senior Citizens Law Center, and Center for Medicare, Advocacy Balanced Budget Act of 1997: Reshaping the Health Safety Net for America's Poor: An Analysis of the Medicaid Provisions. Washington, DC, National Senior Citizens Law Center 1997,

21. United States Censusc Bureau Current Population Survey. Washington, DC 200I, Accessed 20 December 2002.
22. Kaiser Commission on Medicaid and the Uninsured Key Facts: Immigrants' Health Care Coverage and Access. Washington, DC, Henry J. Kaiser Family Foundation 200I,

23. Schur CL and Feldman J Running in Place: How Job Characteristics, Immigrant Status, and Family Structure Keep Hispanics Uninsured. New York, The Commonwealth Fund 200I,

24. Cunningham PJ and Tu HT A changing picture of uncompensated care. Health Aff 1997, I6:167-175

25. Davidoff AJ, LoSasso AT, Bazzoli GJ and Zuckerman S The effect of changing state health policy on hospital uncompensated care. Inquiry 2000, 37:253-267

26. Mann J, Melnick G, Bamezai A and Zwanziger J Managing the safety net: hospital provision of uncompensated care in response to managed care. Adv Health Econ Health Serv Res 1995, I 5:49-77

27. The Commonwealth Fund Task Force on Academic Health Centers A Shared Responsibility: Academic Health Centers and the Provision of Care to the Poor and Uninsured. New York, NY, The Commonwealth Fund 200I,

28. Weissman J Uncompensated hospital care. Will it be there if we need it? JAMA 1996, 276:823-828

29. Dalaker J Poverty in the United States: 2000. United States Bureau of the Census Web site 2002, Accessed 20 December 2002.

30. American Hospital Association Health Forum LLC (1994-1999) Annual Survey of Hospitals. Chicago, American Hospital Association 2000 ,

31. Tumlin KC, Zimmermann W and Ost J State Snapshots of Public Benefits for Immigrants: A Supplemental Report to "Patchwork Policies". Washington, DC, The Urban Institute 1999,

32. Huber PJ The behavior of maximum likelihood estimates under non-standard conditions. In Proceedings of the Fifth Berkeley Symposium on Mathematical Statistics and Probability (Edited by: Berkeley CA) University of California Press 1967, I:221-223

33. White $\mathrm{H}$ A heteroskedasticity-consistent covariance matrix estimator and a direct test for heteroskedasticity. Econometrica 1980, 48:817-30

34. White $H$ Maximum likelihood estimation of misspecified models. Econometrica 1982, 50: I-25

35. Bovbjerg RR, Cuellar AE and Holahan J Market Competition and Uncompensated Care Pools. Washington, DC, The Urban Institute 2000,

36. Fishman LE and Bentley JD The evolution of support for safetynet hospitals. Health Aff 1997, 16:30-47

37. Coughlin TA and Liska D The Medicaid Disproportionate Share Hospital Payment Program: Background and Issues. Washington, DC, The Urban Institute 1997.

38. Gaskin DJ, Hadley J and Freeman VG Are urban safety-net hospitals losing low-risk Medicaid maternity patients? Health Serv Res 2001, 36:25-5I

39. Atkinson G, Helms WD and Needleman J State trends in hospital uncompensated care. Health Aff 1997, 16:233-4I

40. Mann JM, Melnick GA, Bamezai $A$ and Zwanziger J A profile of uncompensated hospital care, 1983-1995. Health Aff 1997, 16:223-32

\section{Pre-publication history}

The pre-publication history for this paper can be accessed here:

http://www.biomedcentral.com/1472-6963/3/1/prepub 